
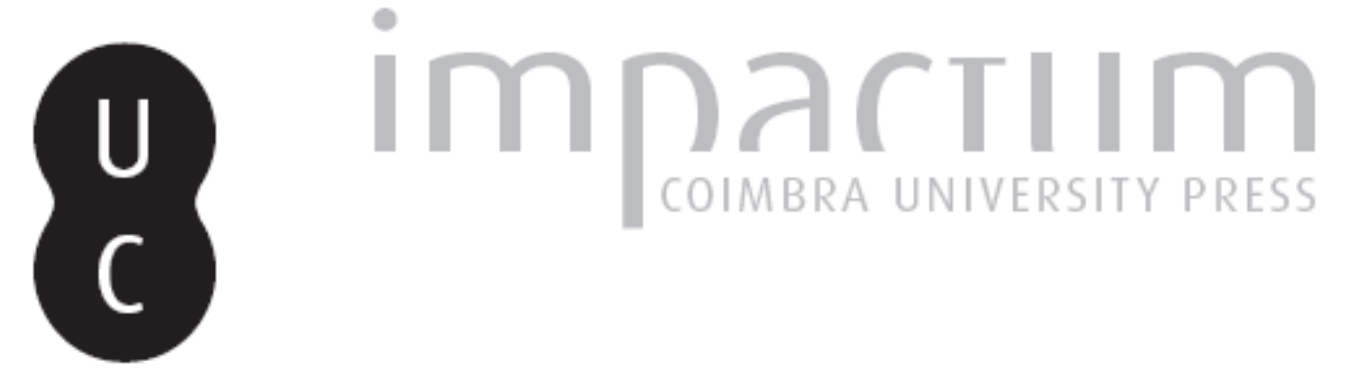

\title{
Viaggio in Italia: o SAAL - Norte e os anos de chumbo
}

\author{
Autor(es): Lobo, Susana
}

Publicado por: Imprensa da Universidade de Coimbra

URL persistente:

URI:http://hdl.handle.net/10316.2/42408

DOI:

DOl:https://doi.org/10.14195/0870-8584_9_2

Accessed : $\quad$ 26-Apr-2023 08:42:08

A navegação consulta e descarregamento dos títulos inseridos nas Bibliotecas Digitais UC Digitalis, UC Pombalina e UC Impactum, pressupõem a aceitação plena e sem reservas dos Termos e Condições de Uso destas Bibliotecas Digitais, disponíveis em https://digitalis.uc.pt/pt-pt/termos.

Conforme exposto nos referidos Termos e Condições de Uso, o descarregamento de títulos de acesso restrito requer uma licença válida de autorização devendo o utilizador aceder ao(s) documento(s) a partir de um endereço de IP da instituição detentora da supramencionada licença.

Ao utilizador é apenas permitido o descarregamento para uso pessoal, pelo que o emprego do(s) título(s) descarregado(s) para outro fim, designadamente comercial, carece de autorização do respetivo autor ou editor da obra.

Na medida em que todas as obras da UC Digitalis se encontram protegidas pelo Código do Direito de Autor e Direitos Conexos e demais legislação aplicável, toda a cópia, parcial ou total, deste documento, nos casos em que é legalmente admitida, deverá conter ou fazer-se acompanhar por este aviso.

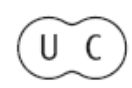




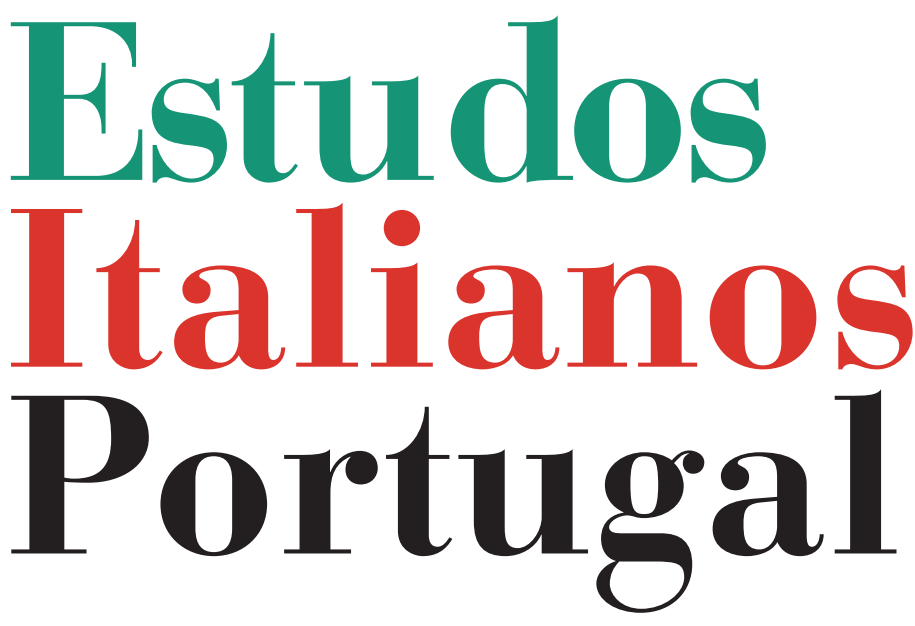

Instituto

Italiano

de Cultura

de Lisboa

Nova Série

$\mathbf{N}^{\circ} 9$ 


\section{VIAGGIO IN ITALIA. O SAAL - NORTE E OS ANOS DE CHUMBO}

SusAna Lobo*

Obra de transiçÃo na filmografia de Roberto Rossellini, que marca o abandono do realismo social e anuncia, em termos de forma e de narrativa, o caminho para um novo modelo de cinema, Viaggio in Italia (1954), como todas as viagens, é uma viagem de descoberta. Descoberta de um país - Itália, que o casal Joyce, Alex (George Sanders) e Katherine (Ingrid Bergman), percorrem no seu Bentley, vindos de Londres, até Nápoles, para, aí, tratarem da venda da villa herdada de um tio, Homer Joyce, situada junto ao Vesúvio; das suas gentes e dos seus costumes - que criticam constantemente e náo compreendem; e do seu passado - cuja presença tanto fascina e inquieta Katherine nas suas visitas ao Museu Nacional de Nápoles e ao Sítio Arqueológico de Cuma. Mas é, também, uma viagem de descoberta pessoal, em que ambos se apercebem, porque verdadeiramente a sós depois de oito anos de casados, do quão pouco se conhecem. No final, após sucessivos desencontros e acusaçóes, decididos a divorciarem-se, acabam por se redescobrir nos braços um do outro, tal como os dois corpos encontrados nas ruínas de Pompeia,

* Arquitecta, Professora do Departamento de Arquitectura da UC. Doutorou-se em 2013 com a tese Arquitectura e turismo: planos e projectos. As cenografias do lazer na costa portuguesa, da 1. a República à Democracia. Editou Pousadas de Portugal. Reflexos da Arquitectura Portuguesa do Século XX (Imprensa da Universidade Coimbra, 2006). 
28 Susana Lobo

no meio da multidão que assiste a uma procissão religiosa. É o milagre da fé sobre a complexidade da existência humana.

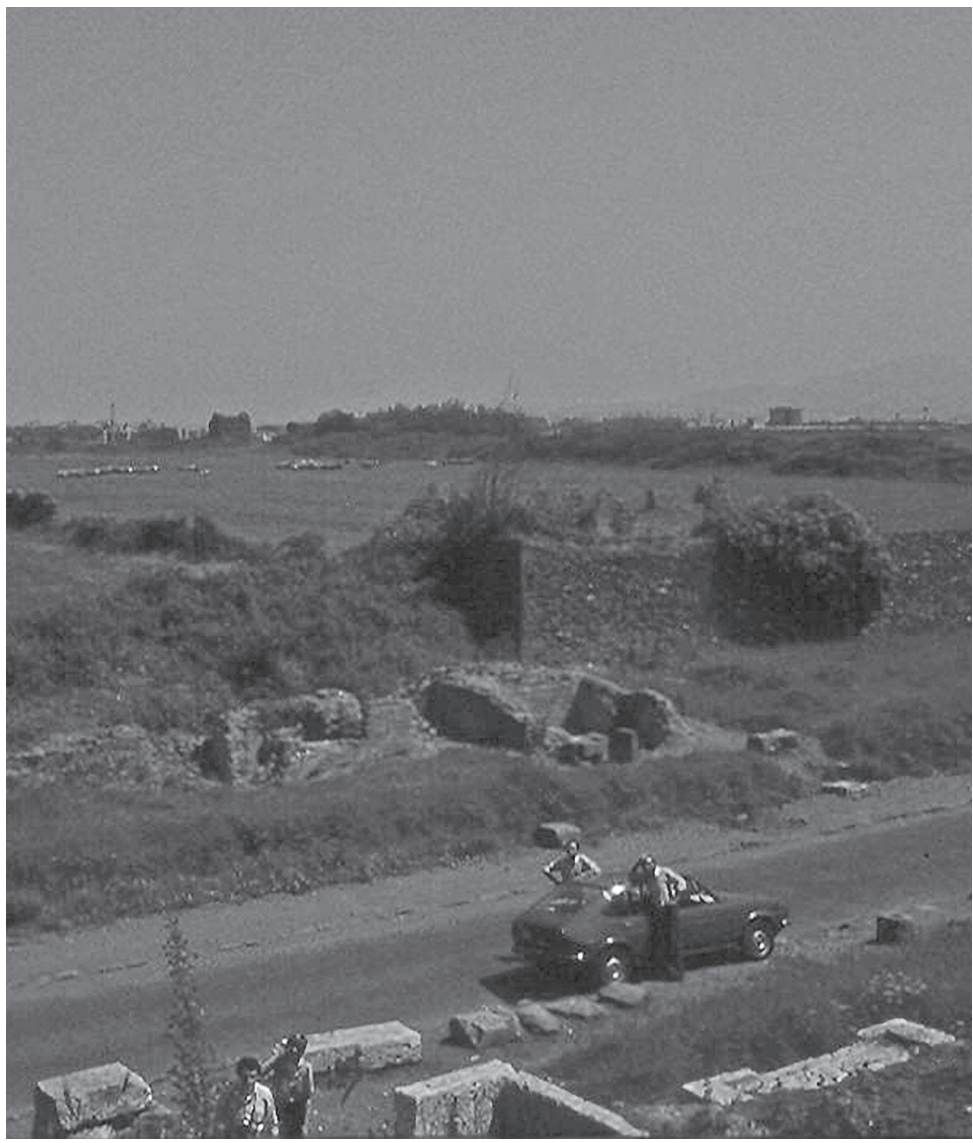

Figura 1. Via Appia, entre Roma e Sabaudia (fotografia de Nuno Portas, Arquivo Alexandre Alves Costa). 
Vinte e três anos depois, Nuno Portas, Álvaro Siza Vieira e Alexandre Alves Costa fazem o mesmo trajecto, entre Roma e Nápoles, no seu périplo por Itália para apresentarem o projecto SAAL-Norte. Não conduzem um Bentley, mas um Alfasud azul. E a herança que têm para partilhar é a experiência de uma nova abordagem metodológica à construção da habitação operária e popular. É, nesse sentido, uma viagem de descoberta "inversa", em que o que se pretende é dar a conhecer a realidade portuguesa. Neste processo, acaba, também esta, por ser uma viagem de profunda reflexão, proporcionando a oportunidade aos arquitectos, talvez a primeira desde a extinçáo do Serviço de Apoio Ambulatório Local (SAAL), de ensaiarem e coordenarem um discurso sobre a sua contribuição para aquele programa. Uma espécie de duplo reencontro, uns com os outros e cada um com a sua prática. Mas, aqui, sem qualquer intervenção divina.

\section{"SAAL Portogallo"}

A iniciativa de organizar uma exposição sobre o SAAL em diversas escolas de arquitectura italianas terá partido do arquitecto Emilio Battisti. Professor na Faculdade de Arquitectura do Politécnico de Milăo, é, certamente, através das suas relaçóes com o grupo Il Manifesto, cujo jornal, fundado em 1969, tinha sido lançado pelas Edizioni Dedalo, que se estabelecem os primeiros contactos com os arquitectos portugueses.

Por um lado, desde o início da década de setenta que o grupo acompanhava a evolução da situação política em Portugal, aprofundando ligaçóes, partidárias e pessoais, com vários dos elementos fundadores do Movimento de Esquerda Socialista (MES), de quem Nuno Portas era próximo. Por outro lado, em Setembro de 1972, a revista Controspazio, daquela mesma editora, criada e dirigida por Paolo Portoghesi, havia publicado, pela primeira vez fora da Península Ibérica, 
a obra de Álvaro Siza Vieira, acompanhada por artigos de Nuno Portas e de Vittorio Gregotti ${ }^{1}$. É, também, Gregotti que, a convite de Bernard Huet, apresenta, com Oriol Bohigas $^{2}$, o trabalho do arquitecto português no número especial, de Maio-Junho de 1976, da revista francesa L'Architecture d'Aujourd'hui, dedicado a Portugal, no qual o SAAL é, também, objecto de destaque.

A Emilio Battisti junta-se, na organização da exposição, o arquitecto Francesco Marconi. Formado por Roma ${ }^{3}$, onde conhece e trabalha com Franco Purini, vem a Portugal em 1974, como tantos outros nesta altura, para testemunhar, ao vivo, a "revolução do povo", acabando por se envolver directamente com o programa SAAL, do qual viria a ser o arquitecto-coordenador das brigadas técnicas da Conchada, Relvinha, Fonte do Bispo e Quinta da Nora, em Coimbra ${ }^{4}$. $\mathrm{Na}$ sequência desses dois anos de trabalho, publica, em Fevereiro de 1977, com Paula de Oliveira, Politica e progetto: un'esperienza di base in Portogallo, livro integrado na secção "Casa, Città, Territorio" da Feltrinelli Economica, coordenada, precisamente, por Emilio Battisti, e com prefácio de

1 Nuno Portas, com "Note sul significato dell'architettura di Álvaro Siza nell'ambiente portoghese", e Vittorio Gregotti, com "Architettura recente di Álvaro Siza Vieira”. Cf. Controspazio, 9, settembre 1972.

${ }^{2}$ As contribuições de Gregotti e Bohigas são apresentadas sob o título "La Passion d'Alvaro Siza”, com introdução do próprio Bernard Huet, sendo que o texto do arquitecto catalão já havia sido publicado, nesse mesmo ano, na revista Arquitecturas Bis, juntamente com o artigo "Arquitectura en las margenes", de Rafael Moneo, ambos referentes à obra de Álvaro Siza Vieira. Cf. L'Architecture d'Aujourd'hui, 185, mai-juin 1976 e Arquitecturas Bis, 12, 1976.

${ }^{3}$ Pela Università degli Studi di Roma La Sapienza, que frequenta entre 1968 e 1972, licenciando-se com a tese Organismi ospedalieri e origine sociale della malattia, realizada sob a orientação de Giuseppe Perugini.

${ }^{4}$ Apenas a Relvinha viria a ser construída, numa segunda versão do projecto, já da autoria dos arquitectos Carlos de Almeida ( $1 .^{\text {a }}$ fase - habitação unifamiliar) e Rogério Alvarez (2. a fase - habitação colectiva). Cf. José António Bandeirinha, O Processo SAAL e a Arquitectura no 25 de Abril de 1974, Coimbra, Imprensa da Universidade de Coimbra, 2007. 
Nuno Portas, a que se juntava, ainda, a contribuição de Alexandre Alves Costa com o texto de introdução às intervençôes do SAAL no Porto 5 . Na verdade, já três meses antes, em Novembro de 1976, a revista Casabella, dirigida, à altura, por Bruno Alfieri, havia contado com o testemunho de Francesco Marconi sobre essa experiência em "Portogallo: operação SAAL", artigo de abertura daquele número. Inclusivamente, figurava como único elemento de composição gráfica da capa um autocolante realizado pelo arquitecto para a Associação de Moradores da Relvinha, com o slogan "A casa do proletário não pode sair do seu salário".

Em ambos os textos, Marconi faz uma análise da evolução do SAAL dentro do contexto político português e, em particular, no âmbito dos movimentos populares de luta pelo direito à habitação no pós- 25 de Abril, apresentando, como referência, alguns projectos de diferentes tipos de intervençóes (urbanas, suburbanas e rurais) realizados pelas brigadas técnicas do SAAL para vários pontos do país. Destaca-se a especificidade metodológica e a originalidade da abordagem preconizada neste género de operaçóes, em que o processo assume preponderância sobre o produto final. Não se tratava apenas de construir casas, mas de mobilizar e de envolver as populaçóes carenciadas, organizadas formalmente em unidades de vizinhança (bairro, freguesia ou zona), na discussão e na construção do seu próprio habitat, colectivo e individual, subordinando a oferta e os mecanismos da produção directamente às necessidades da procura. Nesta aproximação ao real, o papel das brigadas técnicas ganha especial relevância, funcionando, por um lado, como agentes de mediação entre a administração pública e o poder popular, num difícil equilíbrio entre autonomia e contaminação, e clarificando, por

\footnotetext{
${ }_{5}$ Paula Oliveira, Francesco Marconi, Politica e progetto: un'esperienza di base in Portogallo, Milano, Feltrinelli Economica, 1977.

${ }^{6}$ Francesco Marconi, "Portogallo: operação SAAL", Casabella. Rivista di Urbanistica Architettura e Disegno Industriale, 419, 1976, pp. 2-21.
} 
outro, através das opções de projecto - ou seja, através do campo disciplinar da Arquitectura -, as aspiraçóes e os interesses de uma sociedade em transformação. Neste sentido, o programa SAAL é entendido como prática política ${ }^{7}$. E este será o mote para a exposição em Itália ${ }^{8}$.

\section{“L'ARCHITETTURA COME PRATICA POLITICA"}

Os anos setenta, em Itália, como no resto da Europa, são anos de forte contestação política e social, assistindo-se a uma crescente militância em torno das organizaçóes extra-parlamentares nascidas dos movimentos de luta estudantil, popular e proletária do final da década anterior. $\mathrm{O}$ agravamento da situação económica do país, com a crise petrolífera mundial de 1973, e o descontentamento generalizado da sociedade italiana em relação à ordem institucional estabelecida, com democratas-cristãos e socialistas a revezarem-se continuamente no poder, conduziria a uma radicalização de posiçóes ideológicas, à esquerda e à direita, com inevitáveis repercussóes nas formas de reivindicação adoptadas e que seria extremada no confronto armado entre opostos políticos e entre estes e as forças da autoridade. Neste clima de tensão, o Partido Comunista Italiano ganha um fôlego renovado, afirmandose como a segunda força política nas eleições de 20 de Junho de 1976 , a poucos pontos percentuais da Democracia Cristá, no que seria o seu melhor resultado de sempre. No entanto, as expectativas criadas entre a massa eleitoral trabalhadora de uma mudança estrutural no programa do governo, a favor do estado social e da contestação à hegemonia capitalista, logo seriam frustradas perante a abstenção negociada dos comu-

\footnotetext{
${ }^{7}$ Uma prática que, segundo Nuno Portas, não devia ser confundida "con la direzione politica del 'poder popular". Cf. Nuno Portas, "Prefazione”, Paula Oliveira, Francesco Marconi, cit., p. 24.

${ }^{8}$ Exposição que conta, ainda, com a colaboração de Emilio Marconi e de Gianni Sebastiani.
} 
nistas na formação do novo governo Andreotti e na sequente implementação de profundas medidas de austeridade. $\mathrm{O}$ PCI de Enrico Berlinguer rejeitava, assim, qualquer pretensão revolucionária de luta pelo poder, abrindo-se à construção de consensos que garantissem a manutenção da república democrática, numa perspectiva reformista que leva ao escalar da contestação popular (que passa à acção directa com expropriaçôes proletárias e a ocupação de casas) e da violência armada e terrorista nas ruas. Sáo os "anos de chumbo" da história da democracia italiana.

É neste contexto de intensa mobilizaçáo e confronto que os arquitectos portugueses são convidados a irem a Itália falar do SAAL, uma experiência inovadora de participaçáo democrática - "construir para o povo, com o povo" - que encontra eco num país à beira da revolução.

\section{"Le Brigate SAAL: mostra Degli interventi"}

O convite às "Brigadas Técnicas das Antas, Gondomar, Lapa, Leal, Maceda, Massarelos, Miragaia, Prelada e S. Victor para exporem os trabalhos efectuados nas respectivas zonas em diversas Faculdades de Arquitectura italianas" aparece referenciado numa circular, de 11 de Junho de 1976, dirigida pelo Arquitecto Pedro Ramalho à Comissão Coordenadora do SAAL-Norte. "Considerando as Brigadas convidadas que seria do maior interesse alargar o âmbito da participação a todas as restantes Brigadas, de acordo com a entidade organizadora que se reserva o direito da selecçáo", o arquitecto solicitava àquela Comissão a divulgação do convite junto das outras equipas. A exposição estava agendada para Outubro, pelo que os trabalhos deveriam ser entregues até 15 de Setembro.

\footnotetext{
9 Pedro Ramalho, "À Comissão Coordenadora do SAAL-Norte”, documento dactilografado, Porto, 11-6-1976. (Universidade de Coimbra, Centro de Documentação 25 de Abril, Arquivo José António Bandeirinha, Pasta SAAL-Norte Circulares/Expediente Geral).
} 
Deste documento fica explícito que o contacto é estabelecido directamente com as Brigadas Técnicas e, especificamente, com aquelas, do que podemos deduzir que havia um conhecimento prévio do trabalho realizado, possivelmente através da revista L'Architecture d'Aujourd'hui, que, no seu número de Maio-Junho, publica as operaçóes das Antas e de S. Victor, mas, do SAAL-Norte, apenas estas duas. O facto de se incluírem no convite sete outras operaçôes deixa, por isso, subentendido que esse conhecimento seria mais profundo e, aí, o envolvimento de Francesco Marconi na organização da exposiçáo terá sido determinante, uma vez que se encontrava já a preparar o seu livro com Paula de Oliveira.

Relevante é constatar que de todo o programa SAAL o interesse dos italianos centra-se nas intervençóes do SAAL-Norte. Este enfoque resulta, certamente, da proximidade que este núcleo particular de operaçóes estabelece, no que respeita à filosofia das intervençôes, com a tradição cultural italiana. A diferença estava, agora, no contexto. Se em Itália a implantação dos novos conjuntos residenciais seguia a tendência de alojar as classes desfavorecidas na periferia das cidades, no Porto defendia-se a manutenção das populaçóes pobres no centro da cidade, "procura[ndo] alicerçar as novas habitaçôes num processo de identidade adquirido ao longo do tempo" ${ }^{10}$. Essa é a especificidade do SAAL-Norte dentro do programa SAAL nacional e um dos princípios que vieram a determinar a maior coerência deste conjunto de operaçóes em relação a outros. Outro princípio seria o da própria constituição das brigadas técnicas, que contam com o envolvimento directo de professores e alunos da recém-instituída Faculdade de Arquitectura do Porto. Uma escola em pleno processo de refundação pedagógica e que encontra no SAAL uma oportunidade concreta para transpor e testar no território do real uma nova metodologia de ensino. Naturalmente,

${ }^{10}$ José António Bardeirinha, cit., p. 249. 
é, também, este confronto entre teoria e prática que interessa às escolas italianas aprofundar.

Mas, talvez, o dado mais significativo da circular enviada pelo arquitecto Pedro Ramalho é a sua data, a qual vem confirmar que o convite é realizado, por um lado, pouco antes das eleiçóes italianas de 20 de Junho de 1976, e, por outro, antes, ainda, do fim do programa SAAL, em Outubro de 1976. Curioso é que nesse mesmo dia 11 de Junho de 1976 terminava, em Vancouver, a Conferência da ONU sobre Estabelecimentos Humanos e o Fórum Habitat I, no qual Alexandre Alves Costa, enquanto assessor da delegaçáo portuguesa, participa com uma comunicação, precisamente, sobre o SAAL-Norte.

Das restantes brigadas convidadas a integrar a exposição, respondem ao desafio as da Arrábida ${ }^{11}$ e das Fontainhas ${ }^{12}$ e as de Chaves de Oliveira e Francos ${ }^{13}$. Cada brigada ficou responsável por elaborar e produzir, em cópia heliográfica, os respectivos painéis de apresentaçáo, num máximo de três por operação, com a dimensão de um metro por dois e estruturados a partir de uma matriz comum, definida pela Comissão Coordenadora, que garantia, também ao nível gráfico, a unidade do todo. No entanto, provavelmente devido ao desfecho do programa SAAL - extinto no mês previsto para a inauguração da exposição -, a mesma acabaria por ser adiada.

De facto, nova referência a este convite é feita num comunicado resultante do Plenário das Brigadas Técnicas do Porto, de 2 de Novembro $^{14}$, que, em nota anexa, listava, para além de toda a bibliografia existente e em preparação sobre

\footnotetext{
${ }^{11}$ Participação confirmada pelo arquitecto Camilo Cortesão.

${ }^{12}$ Segundo o arquitecto Manuel Mendes.

${ }^{13}$ Estas duas últimas, de acordo com o testemunho do arquitecto Alexandre Alves Costa, mas não nos foi possível confirmar.

14 "O SAAL como alternativa de planeamento", documento dactilografado, Plenário das Brigadas Técnicas, Porto, 2-11-1976 (Universidade de Coimbra, Centro de Documentação 25 de Abril, Arquivo José António Bandeirinha, Pasta SAAL-Norte Circulares/Expediente Geral).
} 
o SAAL-Norte, os seminários internacionais e as exposições agendadas para os anos de 1976 e 1977 . Entre estas, aludia-se a uma "exposição simultânea em 8 Escolas de Arquitectura" italianas, ainda que sem qualquer indicação da data da sua realização. Cinco meses depois, Nuno Portas, Álvaro Siza Vieira e Alexandre Alves Costa são recebidos em Milão por Emilio Battisti. "Debaixo do braço" levam oito rolos de painéis, um por cada uma das escolas que estava previsto visitarem, e das máos do arquitecto italiano recebem as chaves de uma "bella machina" - um Alfa Romeo Alfasud alugado - que os acompanhará na sua viagem em Itália.

"AMBITO PROBLEMATICO: ABITAZIONI, CLASSI SOCIAL, TERRITORIO"

A presença dos arquitectos portugueses em Itália dá outra dimensão à iniciativa ${ }^{15}$. Cada exposição era, assim, complementada com a realização, em paralelo, de um seminário que contava com o testemunho pessoal de três dos principais protagonistas do SAAL, em particular do SAAL-Norte. Em cada Faculdade, onde são sempre recebidos por um grupo de professores, montavam a exposição e, na manhã seguinte, faziam a apresentação. Nuno Portas era o primeiro a falar, explicando, num italiano perfeito, todo o processo da criação do programa SAAL e seus antecedentes. Seguiam-se, inicialmente em português e com tradução de Portas ${ }^{16}$, Alexandre Alves Costa e Álvaro Siza Vieira, focando, o primeiro, a intervenção

\footnotetext{
${ }^{15}$ Não sabemos se a viagem de Portas, Siza e Alexandre Alves Costa a Itália estaria já programada aquando do convite feito às brigadas, em Junho de 1976. Parece-nos mais plausível esta hipótese ter surgido como resultado da extinção do processo SAAL e, daí, numa perspectiva mais institucional, a presença de Nuno Portas, e, numa relação mais directa com o trabalho de campo e com as comissões de moradores, de Alexandre Alves Costa.

${ }^{16}$ Depois das primeiras sessões, esta dinâmica seria alterada. Na conferência comemorativa dos trinta anos do SAAL, realizada nas Belas-Artes do Porto, Alexandre Alves Costa contava que "verificámos o seguinte: nós falávamos um minuto e o Portas
} 
SAAL no Porto, do ponto de vista processual e metodológico, e a participação dos moradores, e, o último, a operação de $S$. Victor, ambos com o apoio de diapositivos. Depois, partiam para a escola seguinte e voltavam a fazer tudo de novo ${ }^{17}$.

O itinerário foi definido, pela organizaçáo, de acordo com as escolas envolvidas. A primeira a ser visitada seria, naturalmente, a Faculdade de Arquitectura do Politécnico de Miláo, que até Outubro de 1976 tinha sido presidida por Paolo Portoghesi e da qual Emilio Battisti era professor. Segue-se a Faculdade de Arquitectura do Politécnico de Turim, onde o seminário tem lugar no dia 19 de Abril, às 9h30, embora a exposição já estivesse a decorrer desde o dia 12. Esta informação, retirada do cartaz de divulgação do evento, permitenos deduzir que o início da viagem dos arquitectos portugueses é, necessariamente, anterior a essa data, uma vez que transportavam consigo os painéis realizados pelas brigadas. Apontamos, por isso, o dia 11 de Abril de 1977, uma segunda-feira, como a data provável da sua chegada a Itália. De Turim, partem para Veneza, onde são aguardados no Instituto Universitário de Arquitectura, à altura dirigido por Carlo Aymonino. Aqui, o seminário terá tido lugar no dia 20 de Abril, visto que às $9 \mathrm{~h} 30 \mathrm{da}$ manhá seguinte Portas, Siza e Alves Costa encontravam-se já a falar em Pescara, na Faculdade de Arquitectura da Universidade Livre Gabriele d'Annunzio. A 22 de Abril, também às 9h30, estava prevista a realização do seminário na Faculdade de Arquitectura da Universidade La Sapienza, em Roma. No entanto, devido a uma greve dos alunos, este seminário nunca chegaria a efectuar-se, embora a exposiçáo já estivesse montada, desde o dia 18 de Abril, e

falava três e, então, desconfiávamos. Traduzia eficazmente e depois fazia o comentário, dizendo exactamente o contrário. Decidimos acabar com o tradutor”. Alves Costa passou a fazer a apresentação em francês e Siza num misto de português e italiano (filmagens da conferência cedidas por Ana Alves Costa).

${ }^{17}$ Os painéis em cópia heliográfica ficaram em cada uma das escolas, permitindo que a exposição se prolongasse para além da presença dos arquitectos portugueses. 
os arquitectos portugueses a tivessem visitado com Franco Purini e Francesco Marconi. Depois do fim-de-semana e do feriado do 25 de Abril, seguem-se, no dia 26, a Universidade da Calábria, em Cosenza, no dia 27, o Instituto Universitário Estatal de Arquitectura de Reggio Calabria, e, no dia 28, a Faculdade de Arquitectura de Palermo. Tendo tido que regressar a Portugal mais cedo, Nuno Portas já não acompanha a visita a esta última Faculdade, onde Siza e Alves Costa são recebidos por Pierluigi Nicolin, Roberto Collovà, Marcella Aprile, Franco Castagnetti e Teresa la Rocca. A exposição em Palermo sobre o "S.A.A.L. Portogallo" dura de 26 de Abril a 4 de Maio e seria acompanhada pela reportagem fotográfica "Una giornata con i braccianti portoghesi che occupano i latifondi, sett. 75", da autoria do arquitecto-fotógrafo Fausto Giaccone, sobre a Reforma Agrária em Portugal.

Em todas as Faculdades a receptividade à iniciativa é enorme, contando com a assistência de grande número de professores e alunos. Nos debates, abertos após as sessóes de apresentação, dominam as questóes políticas mais do que as disciplinares, sobretudo entre os estudantes, que "queriam saber como era a revolução"18. Interessava-lhes, também, o tema da participação, então em voga, que, "de Roma para baixo", estava fortemente associada à questão da autoconstrução $^{19}$. Mas não deixavam, certamente, de ser importantes os problemas práticos da construção e, em particular, os da construção da habitação popular, e, nesse sentido, a apresentação de Álvaro Siza Vieira causa grande impacto ao defender que "a qualidade é respeito pelo povo" 20 .

${ }^{18}$ Testemunho de Alexandre Alves Costa. Entrevista realizada a Nuno Portas, Álvaro Siza Vieira e Alexandre Alves Costa a 2-6-2014.

${ }^{19}$ Segundo Michelle Cannatà. Entrevista realizada a 23-5-2014.

${ }^{20}$ Frase com que Siza acabava sempre a apresentação dos seus projectos para o SAAL-Norte, segundo o testemunho de Eduardo Souto Moura no Simpósio SAAL: Em Retroprospectiva, realizado, no dia 10 de Maio de 2014, no auditório da Fundação Serralves, com curadoria de Delfim Sardo. 

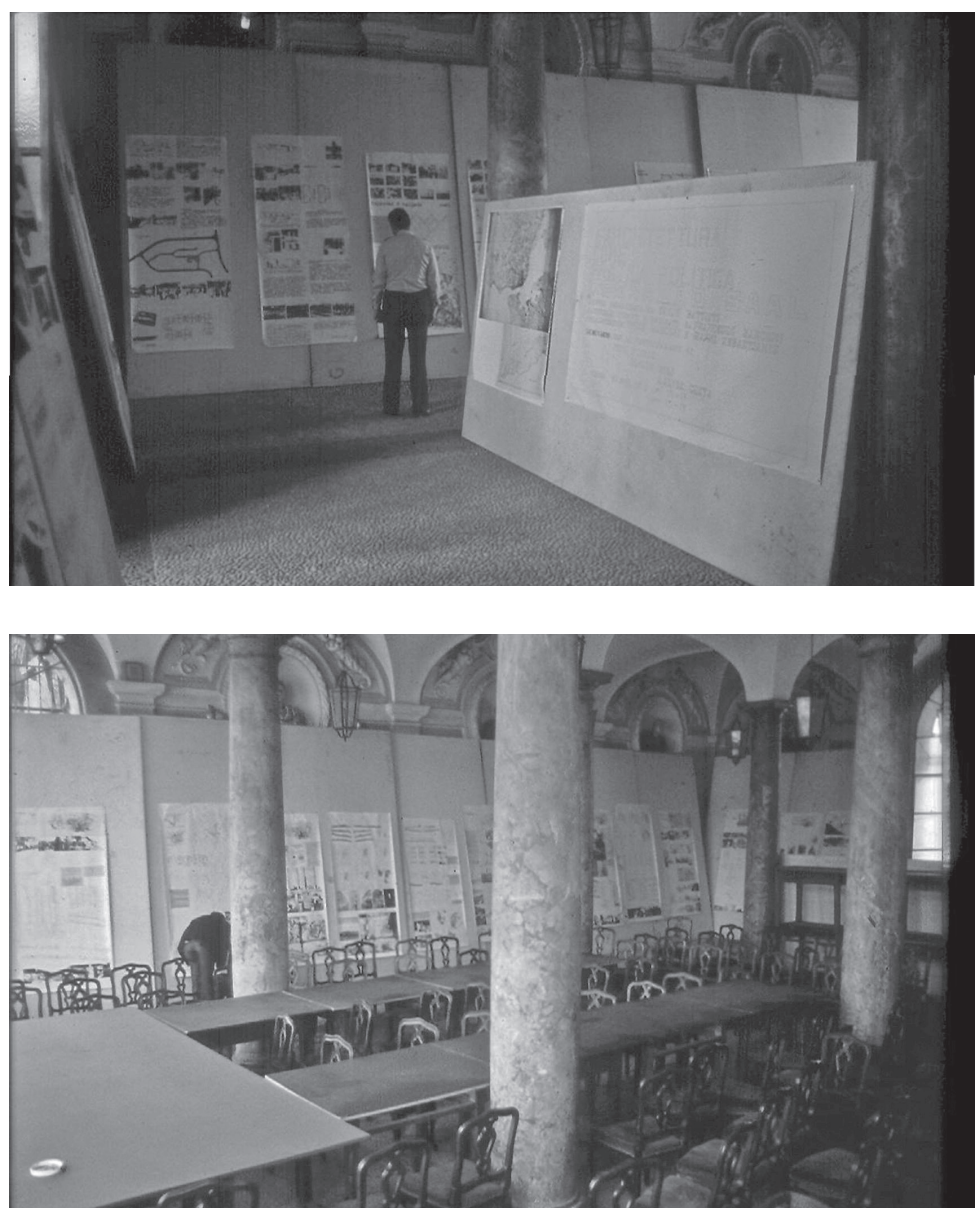

Figuras 2 e 3. Faculdade de Arquitectura do Politécnico de Milão (fotografia, Arquivo Alexandre Alves Costa).

No cartaz de abertura da exposição, lê-se: "L'Architettura come Pratica Politica: Operação SAAL, Mostra organizzata da Emilio Battisti, Materiale editrice [?] da Francesco Marconi, Collaboratori Emilio Marconi e Gianni Sebastianni, Seminario con la participazione di Nuno Portas, Álvaro Siza, A. Alves Costa”. 

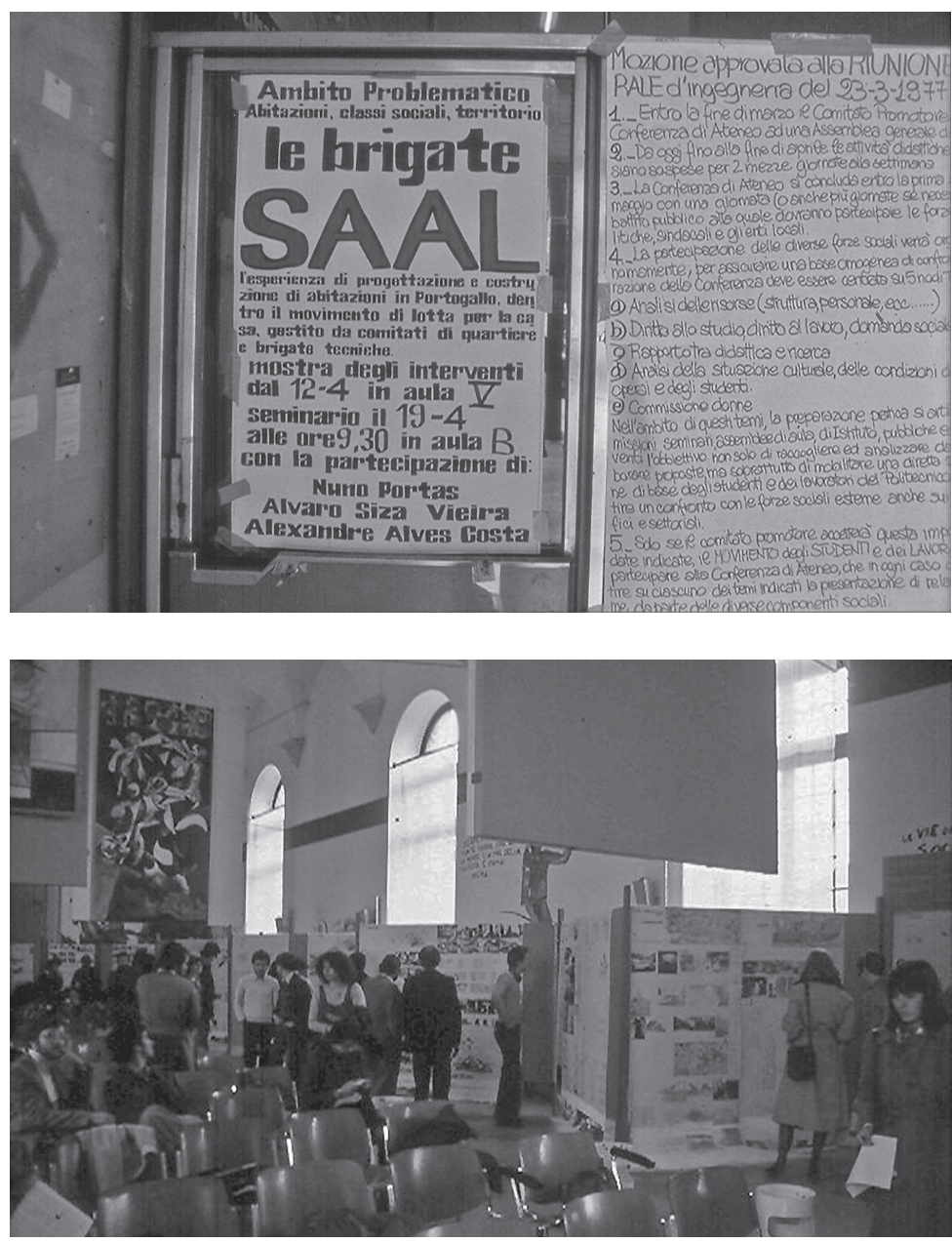

Figuras 4 e 5. Faculdade de Arquitectura do Politécnico de Turim (fotografia, Arquivo Alexandre Alves Costa).

No cartaz, lê-se: "Ambito Problematico: Abitazioni, classi sociali, territorio, Le brigate SAAL, l'esperienza di progettazione e costruzione di abitazioni in Portogallo, dentro il movimento di lotta per la casa, gestito da comitati di quartiere e brigate tecniche". 


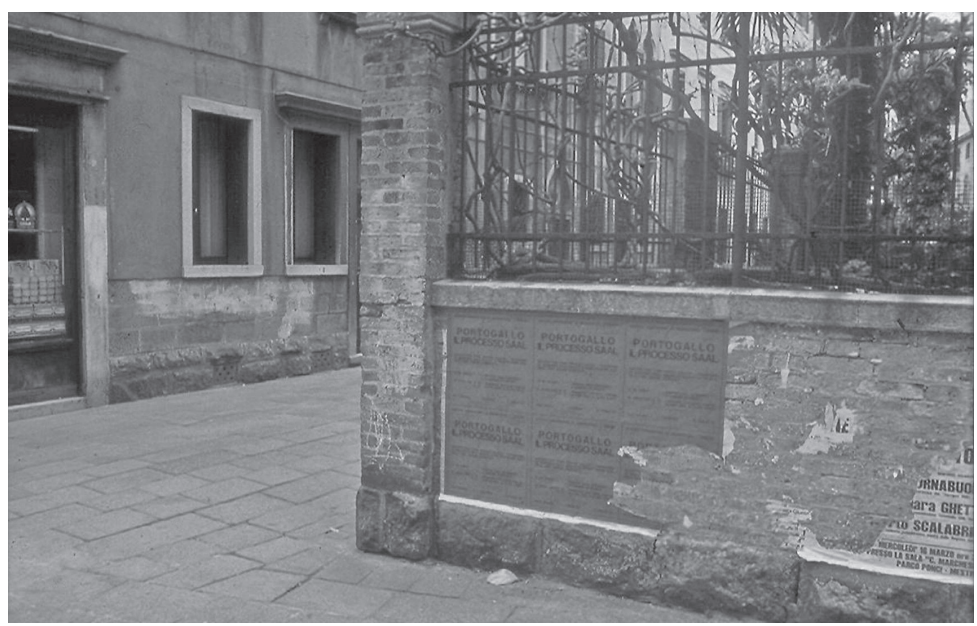

Figura 6. Cartazes "Portogallo, Il Processo SAAL" na rua, Veneza (fotografia, Arquivo Alexandre Alves Costa).

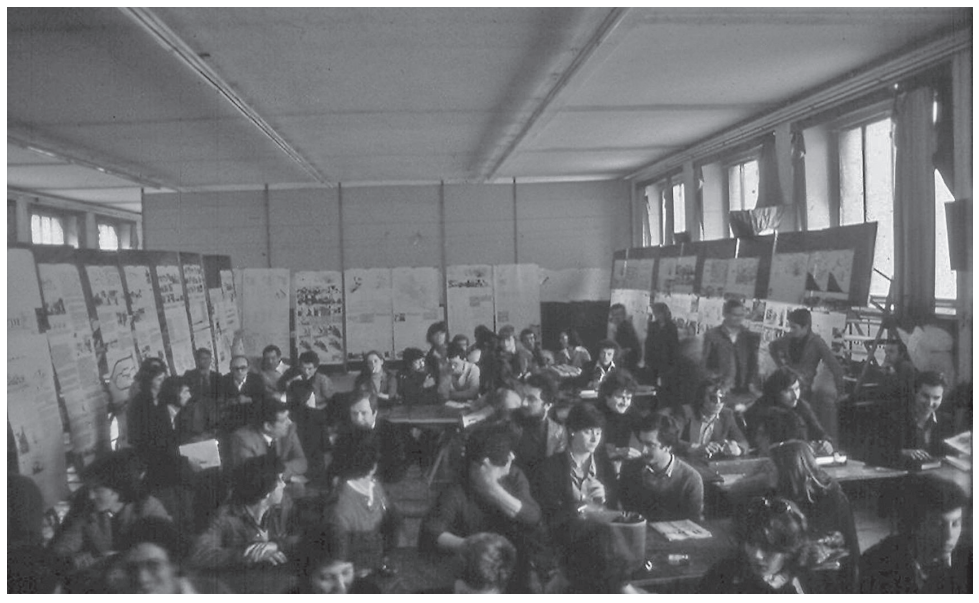

Figura 7. Instituto Universitário de Arquitectura de Veneza (fotografia, Arquivo Alexandre Alves Costa). 

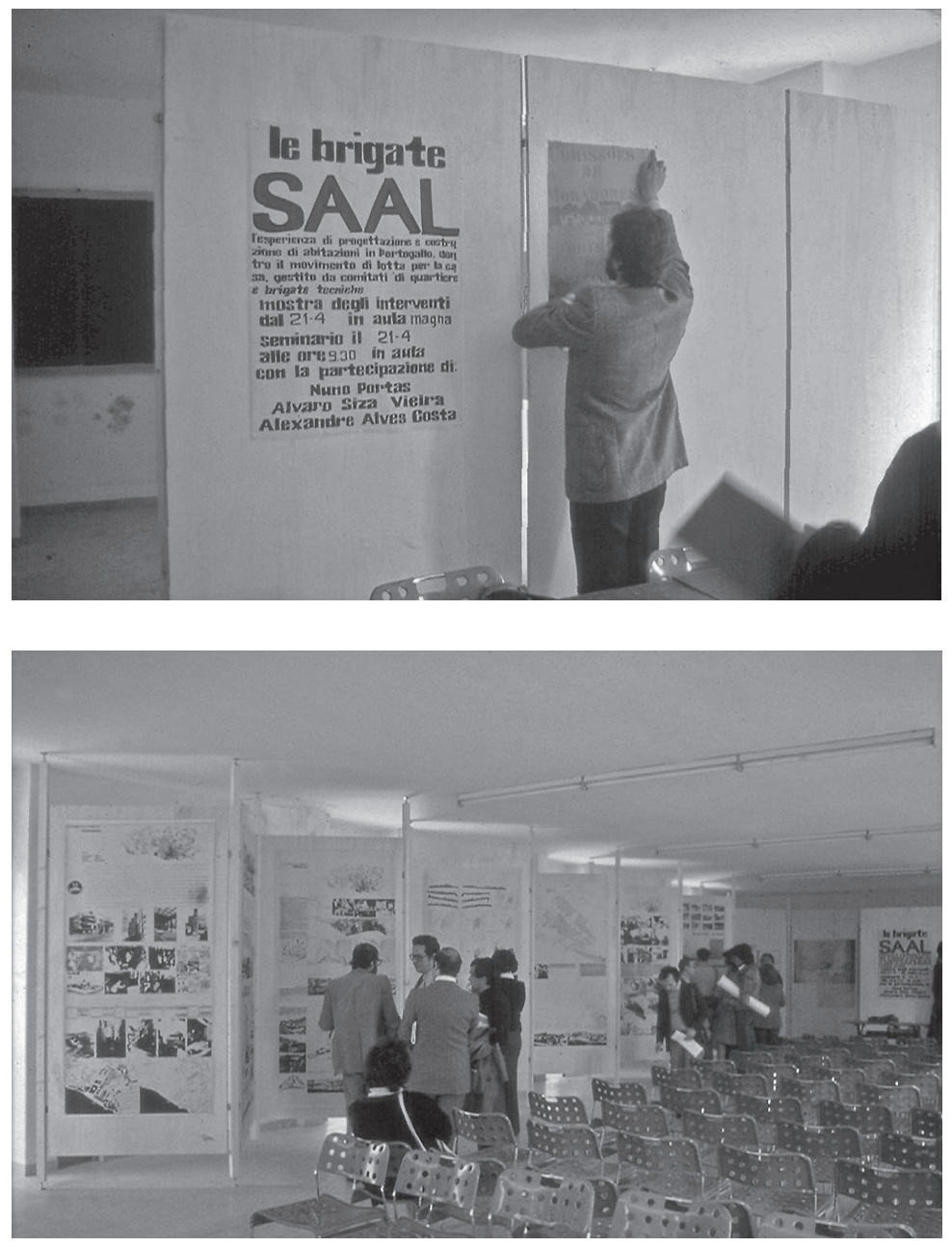

Figuras 8 e 9. Faculdade de Arquitectura da Universidade Livre Gabriele d'Annunzio, Pescara (fotografia, Arquivo Alexandre Alves Costa). 

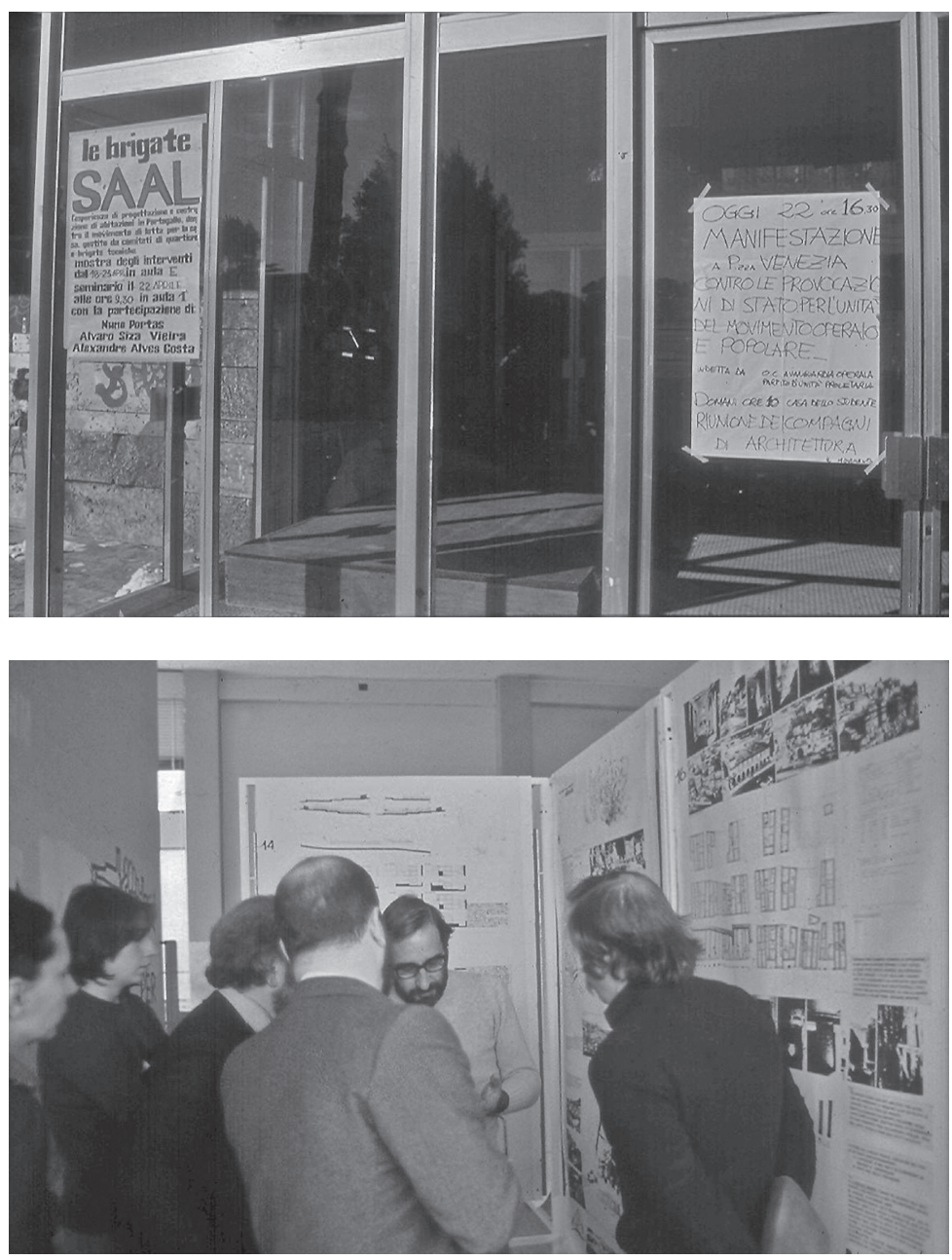

Figuras 10 e 11. Faculdade de Arquitectura da Universidade de Roma La Sapienza (fotografia, Arquivo Alexandre Alves Costa). 


\section{S.A.A.L.}

mostra

incontro

\section{PORTOGALLO}

26 aprile. 4 maggio 1977 ore $10,00 \cdot 13,00 / 16,00 \cdot 18,00$ aula 9 della facolta di architettura di palermo

28 aprile 1977 ore 10,00 aula magna della facolta di architettura

NUNO PORTAS

A.SIZA VIEIRA

A.ALVES COSTA responsabile delle s.a.a.l. $/$ nord

Una giornata con i braccianti portoghesi che occupano i latifondi, sett.75 mostra reportage fotografico di fausto giaccone

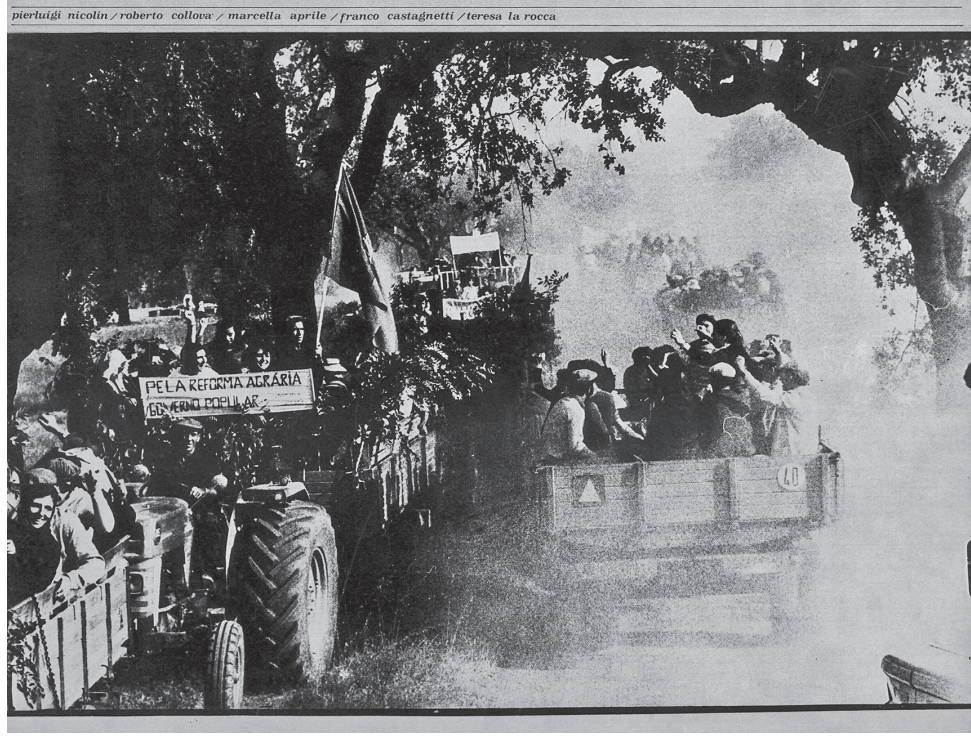

Figura 12. Cartaz "SAAL Portogallo", Palermo (fotografia, Arquivo Distrital do Porto, Arquivo Alexandre Alves Costa, Referência PT/ADPRT/AC/FFH-SAALN/DP-AAC/029/26.015.001). 
Com um programa intenso de exposiçóes e seminários, pouco tempo tiveram os arquitectos portugueses, nesta viagem, para "descobrir" o que quer que fosse. Ainda assim, por iniciativa de Nuno Portas, acabam por visitar uma ou outra obra de arquitectura. As primeiras seriam as recentes intervençóes de Carlo Aymonino e Aldo Rossi no conjunto residencial económico Gallaratese, em Milão, a caminho do qual se perderam várias vezes. Também, no trajecto de Veneza para Pescara, aproveitam para passar, à noite, em Rimini e ver o Templo Malatestiano de Leon Battista Alberti, que Portas queria confirmar se "era assim táo bom quanto diziam”. Já em Roma, por causa da greve dos alunos e por apanharem o fim-de-semana prolongado do feriado de 25 de Abril, tiveram mais disponibilidade. Passearam pela cidade com Francesco Marconi e visitaram, em Trastevere, a Igreja do Convento de Santa Maria dei Sette Dolori, de Francesco Borromini, e, no Tiburtino, o quarteiráo habitacional INA-Casa de Ludovico Quaroni e Mario Ridolfi, manifesto do neorrealismo em arquitectura, que, segundo o comentário de Nuno Portas no local, "já visitavam como se fosse um centro histórico". Por fim, de Roma em direção ao sul, percorrem parte da antiga Via Appia a caminho de Sabaudia, uma das Città Nuove de fundação fascista e símbolo do racionalismo italiano, que também visitaram.

Cumprido o programa oficial da viagem, Siza e Alves Costa permanecem mais uns dias em Palermo, onde acabam por assistir à celebração do $1 .^{\circ}$ de Maio em Portella della Ginestra, lugar mítico da história do movimento comunista italiano na Sicília. De regresso, voltam a Roma para entregar o Alfasud e apanhar o aviáo para Portugal. Provavelmente no dia seguinte, segunda-feira, dia 2 de Maio de 1977. Estiveram em Itália 22 dias.

Se a viagem a Itália foi, por um lado, uma oportunidade de "publicidade honesta" e de divulgação internacional do programa SAAL, "sem consequências, nem para lá nem para câ", 
por outro, "foi uma experiência muito importante", "foi uma forma de parar" e "tomar consciência" sobre uma coisa que tinha acabado de acontecer. E obrigou os arquitectos portugueses a montar um discurso, a sintetizá-lo e transformá-lo em matéria comunicável. Algo que não tinha sido possível na urgência do processo. Nesse sentido, marca, também, como o filme de Rossellini, um momento de transição, entre o "sonho (im)possível" ${ }^{21}$ e a memória possível, abrindo o caminho para uma reflexão autocrítica que, ainda hoje, está por se fazer ${ }^{22}$.

${ }^{21}$ Alexandre Alves Costa, "Anotações para sete imagens", conferência proferida no Simpósio SAAL: Em Retroprospetiva.

${ }^{22}$ A autora agradece a todos os que contribuíram para a realização deste artigo. Muito em particular, aos arquitectos Nuno Portas, Álvaro Siza Vieira e Alexandre Alves Costa, que, gentilmente, acederam a uma entrevista conjunta, realizada no dia 2-6-2014, no Porto. Entrevista que só foi possível graças ao Professor Doutor José António Bandeirinha. Infelizmente, não foi possível contar com o testemunho do arquitecto Francesco Marconi. 